\title{
Cannabinoid hyperemesis syndrome: definition, pathophysiology, clinical spectrum, insights into acute and long-term management
}

\author{
Mahesh Gajendran (D) , ${ }^{\prime}$ Joshua Sifuentes, ${ }^{2}$ Mohammad Bashashati, ${ }^{2}$ \\ Richard McCallum
}

'Department of Internal

Medicine, Texas Tech

University Health Sciences

Center El Paso, Paul L Foster

School of Medicine, El Paso,

Texas, USA

${ }^{2}$ Department of

Gastroenterology, Texas Tech

University Health Sciences

Center El Paso, Paul L Foster

School of Medicine, El Paso,

Texas, USA

${ }^{3}$ Department of

Gastroenterology, Center

for Neurogastroenterology and GI Motility, Texas Tech University Health Sciences Center El Paso, Paul L Foster School of Medicine, El Paso, Texas, USA

\section{Correspondence to} Dr Mahesh Gajendran, Sciences Center El Paso Paul L Foster School of Medicine El Paso, TX 79911, USA; mahesh.gajendran@ttuhsc. edu

Accepted 9 October 2020 Published Online First 28 October 2020 Texas Tech University Health

\section{ABSTRACT}

Although cannabinoid hyperemesis syndrome (CHS) was first reported more than 15 years ago, it still remains an unfamiliar clinical entity among physicians worldwide. CHS is categorized by Rome IV classification as a functional gastroduodenal disorder. It is characterized by stereotypical episodic vomiting in the setting of chronic, daily cannabis use, with cycles decreasing by the cessation of cannabis. CHS is also associated with abdominal pain reduced by hot baths and showers with comparative well-being between attacks. Thus, its clinical presentation resembles 'classic' cyclic vomiting syndrome, but eliciting a cannabis history is crucial in diagnosing this entity. In acute attacks, parenteral benzodiazepines are very effective. For prevention and long-term management, tricyclic antidepressants such as amitriptyline are the mainstay of therapy requiring doses in the range of $50-200 \mathrm{mg} / \mathrm{d}$ to achieve symptom control. In addition, counseling to achieve marijuana cessation, accompanied by antianxiety medications, is necessary for sustaining clinical outcomes. Once the patient is in remission and off marijuana for a period of 6-12 months, then tapering the dose of amitriptyline can be implemented, with the goal of no therapy being achieved in the majority of patients over time. With the legalization of marijuana in many states, CHS will become an increasingly prevalent clinical entity, so educating about CHS is an important goal, particularly for emergency department physicians who generally first encounter these patients.

\section{Linked}

- http://dx.doi.org/10. 1136/jim-2020-001669

\section{Check for updates}

(C) American Federation for Medical Research 2020. No commercial re-use. See rights and permissions. Published by BMJ.

To cite: Gajendran $M$ Sifuentes J, Bashashati M, et al. J Investig Med 2020;68:1309-1316.

\section{INTRODUCTION}

For over 5000 years, cannabis and its derivatives, including the compressed resin (hashish), have been consumed for their psychoactive effects. The earliest archeological evidence for cannabis burning was found in 3500 BC Romanian kurgans, and it is believed to be used in ritual ceremonies. ${ }^{1}$ Israeli archeologists found cannabis residues from an eighth-century BC shrine, providing the first evidence of cannabis use in the ancient Jewish religion. Cannabis was first used in the USA for medicinal purposes around $400 \mathrm{AD} .^{2}$ It was first included in the US Pharmacopeia in 1850, but it was deleted after the passage of the Marihuana Tax Act in 1937, which placed a federal restriction on cannabis use. ${ }^{3}$ In 1996, California was the first state to permit the legal use of cannabis for medicinal purposes under the Compassionate Use Act. As of today, 11 states have legalized recreational marijuana, and 33 states have legalized medical marijuana.

\section{DIAGNOSTIC CRITERIA}

Functional gastrointestinal (GI) disorders are disorders of the brain-gut axis in the absence of organic pathology. ${ }^{4}$ According to Rome IV, functional nausea and vomiting disorders are subclassified into 3 categories: chronic nausea and vomiting syndrome, cyclic vomiting syndrome (CVS), and cannabinoid hyperemesis syndrome (CHS). ${ }^{4} \mathrm{CHS}$ is characterized by stereotypical episodic vomiting in the setting of chronic, daily cannabis use, and the relief of vomiting episodes by the cessation of cannabis use. ${ }^{56} \mathrm{~A}$ key feature of CHS (not emphasized in Rome IV) is abdominal pain, which accompanies the onset of vomiting and is typically located in the epigastrium and radiating diffusely. Both vomiting and abdominal pain can be relieved by hot showers, perhaps due to the accompanying relaxation and distraction. There are periods of well-being or remission lasting from days to weeks between the attacks, which tend to coalesce over time if the entity is not treated. ${ }^{7}$

Clinically, patients with CHS go through 3 phases similar to 'classic' CVS (figure 1).

1. Prodromal phase: It is characterized by nausea without emesis, anorexia, fear of vomiting, and abdominal discomfort. They can usually tolerate a liquid diet.

2. Hyperemesis phase: It is characterized by intractable vomiting and dry retching, which can be briefly relieved by hot showers and can last for many days. This phase is also accompanied by sympathetic overactivity with tachycardia, hypertension, hot flashes, diaphoresis, and trembling. ${ }^{8}$

3. Recovery phase: There is a resolution of symptoms, and patients return to baseline. ${ }^{9}{ }^{10}$

CHS is indistinguishable from 'classic' CVS in terms of the clinical presentation, which can lead to a debate in diagnosis and management. ${ }^{11}$ 


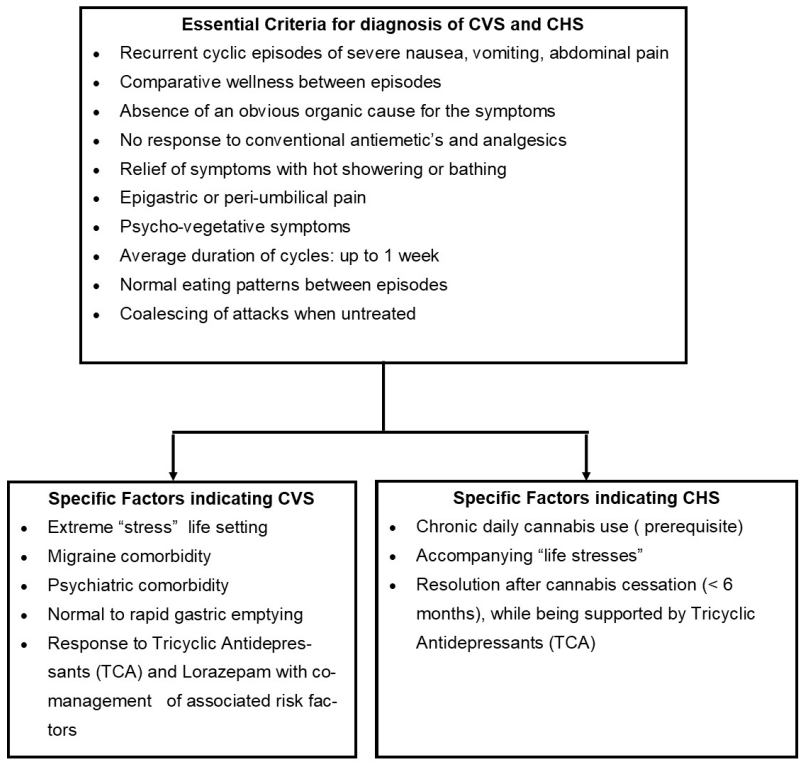

Figure 1 Criteria for diagnosis of cyclic vomiting syndrome (CVS) and cannabinoid hyperemesis syndrome (CHS).

Both disorders affect young people with a male predominance in CHS. ${ }^{12-14}$ The behavior of hot bathing or showering has been linked to CHS; however, more than $10 \%$ of the patients may not have this behavior. ${ }^{15}$ In a study of patients with CVS, 59\% had rapid gastric emptying, 27\% had normal gastric emptying, and $14 \%$ had delayed emptying. ${ }^{16}$ Most of the patients who had delayed gastric emptying were given narcotics or using marijuana surreptitiously. ${ }^{17}$

\section{CASE STUDIES}

In this review article, we present 2 cases (box 1) to illustrate the typical clinical spectrum of CHS and then focus on the manifestations, pathophysiology, and management of this entity using our extensive experience with this entity.

\section{EPIDEMIOLOGY}

The overall prevalence of CHS in the Western world has been reported to be $0.1 \%$, and it is more common in young adults (18-39 years). ${ }^{1819}$ The prevalence of CHS could be as high as $32 \%$ in patients with cannabis use disorder (CUD), which is defined as the ongoing frequent use of cannabis, leading to clinically significant impairment manifested by abuse or dependence symptoms. ${ }^{20}$ The legalization of marijuana will result in a continuing increase in the incidence of CHS. $^{2122}$ As of 2016 , about 41.5 million people in the USA (12.9\% of the population) were cannabis users. ${ }^{23}$ Cannabis use has been reported more commonly in men and unemployed individuals. ${ }^{24}$ The hospitalization rates for cannabisassociated intractable vomiting had increased by $28.6 \%$ from 2010 to 2015 . $^{25}$

One pattern in CHS is recreational marijuana use, often starting during high school or college and continuing on a daily basis. The symptoms of cyclic vomiting episodes usually start after chronic daily intake for approximately 5 years. The amount of cannabis involved has been generally described as heavy and reported in units of blunts, cones, joints, and bongs. However, it is difficult to quantify
Box 1 Case study

Case 1: This case highlights the classical clinical presentation of a patient with cannabinoid hyperemesis syndrome (CHS).

A man in his 40s with a history of gastroesophageal reflux disease (GERD), gastritis, allergic rhinitis, chronic marijuana, and working diagnosis of cyclic vomiting syndrome was referred to the gastrointestinal (GI) motility clinic for further assessment and management. The gastric emptying study was normal, showing $60 \%$ gastric retention at $1 \mathrm{~h}, 28 \%$ retention at $2 \mathrm{~h}$, and $1 \%$ retention at $3 \mathrm{~h}$. The esophagogastroduodenoscopy (EGD) showed mild gastritis with negative Helicobacter pylori testing. He was started on amitriptyline at $10 \mathrm{mg}$ every night at bedtime and was uptitrated to a dose of $40 \mathrm{mg}$ every night at bedtime. Other medications include proton pump inhibitors (PPI) for GERD and lorazepam for anxiety. He was also counseled on marijuana abstinence. With the above management strategy, the patient did very well clinically without episodes of nausea and vomiting as he continued to abstain from marijuana. Now he is in the process of tapering the amitriptyline by $10 \mathrm{mg}$ every month.

Case 2: This case highlights an atypical presentation of CHS, exemplifying how crucial history taking is to diagnose CHS.

A woman in her 60 s with a medical history of type 2 diabetes mellitus (DM), chronic back pain, chronic opioid use disorder, chronic obstructive pulmonary disease (COPD), and generalized anxiety disorder was referred to a GI clinic for assessment of frequent episodes of nausea and vomiting. She reported daily nausea with frequent cycles of vomiting episodes, which has resulted in multiple emergency department (ED) visits over more than 30 y. Associated symptoms include some restlessness and agitation. She was initially diagnosed with gastroparesis $2 \mathrm{y}$ ago with a gastric emptying study and was treated with metoclopramide daily and ondansetron as needed for nausea. However, she continued to be symptomatic and hence referred to our GI motility clinic for a second opinion. On further questioning, she admitted that she has been smoking marijuana for more than $40 \mathrm{y}$. She was also on opioids for chronic back pain since she failed other interventional management, such as multiple spinal injections. This explained the interpretation of the previous gastric emptying study as delayed. We finally diagnosed her with CHS and counseled her about her diagnosis. She had an unproven history of an allergic reaction to amitriptyline, so she was started on doxepin $10 \mathrm{mg}$ once daily, with instructions to uptitrate the dose by $10 \mathrm{mg}$ every week. She was also prescribed lorazepam $0.5 \mathrm{mg}$ as needed for her anxiety in addition to her buspirone $30 \mathrm{mg}$ two times per day. Now 4 mo later, she has achieved a dose of $30 \mathrm{mg}$ doxepin at night, has completely stopped all marijuana intake, and has only very infrequent episodes of nausea.

what is considered to be a high dose of cannabis. In a study from Colorado, about 30\% of the emergency department (ED) visits in patients with CUD were primarily due to CHS. $^{26}$ The main factors that may determine who develops 
CHS among chronic marijuana users include genetic P450 polymorphisms, the type/purity of marijuana, and underlying 'stress'.'

The prevalence of 'classic' CVS symptoms in adults referred for unexplained nausea and vomiting is 3\%-14\%. ${ }^{27}$ About $42 \%-53 \%$ of the patients diagnosed with CVS reported marijuana use. ${ }^{12} \mathrm{~A}$ subgroup of these patients are now identified as having CHS, which is now incorporated as a separate entity within Rome IV. ${ }^{6}$ Patients with CHS may have multiple ED visits, and the diagnosis is often missed mainly due to normal laboratories and diagnostic imaging and hiding the history of marijuana. There is no specific diagnostic test, and it is the constellation of the history and the 'pattern' of the vomiting with accompanying abdominal pain, which eventually leads to the diagnosis. Physicians in the ED settings are typically not experienced with this syndrome, usually making a working diagnosis of gastroenteritis or food poisoning or 'pain medicine seeking behavior', and hence the recurrent ED visits continue to occur. The average time taken to establish a diagnosis of CHS is 4 years. $^{28}$

\section{EXPERIENCE AT OUR ACADEMIC CENTER}

At our academic GI motility referral center, we reviewed 18 patients who met the criteria for CHS and compared them with 27 patients with 'classic' CVS (table 1). The patients answered a 20-minute questionnaire addressing the onset of symptoms, treatment, quality of life, employment, ability to return to social activities, and resume hobbies. ${ }^{29}$ These patients were managed personally with long-term follow-up by one of the authors (RMC) at Texas Tech

Table 1 The demographic and clinical profile of patients with cyclic vomiting syndrome and cannabinoid hyperemesis syndrome at Texas Tech University Health Sciences Center

\begin{tabular}{|c|c|c|c|}
\hline Characteristics & $\begin{array}{l}\text { CHS } \\
n=18\end{array}$ & $\begin{array}{l}\text { CVS } \\
n=27\end{array}$ & $P$ value \\
\hline Median age (IQR) & $35(26,43)$ & $41(33,54)$ & 0.86 \\
\hline \multicolumn{4}{|l|}{ Race } \\
\hline White & $6(33.3)$ & $9(33.3)$ & 1.00 \\
\hline Black & 1 (5.6) & $0(0)$ & 0.40 \\
\hline Hispanic & $10(55.6)$ & $18(66.7)$ & 0.54 \\
\hline Asian & $1(5.6)$ & $0(0)$ & 0.40 \\
\hline Median years of symptoms before diagnosis & $4.5(2.8,10.8)$ & $3(2,6)$ & 0.76 \\
\hline \multicolumn{4}{|l|}{ Etiology } \\
\hline Cannabis only & $5(27.8)$ & $0(0)$ & $<0.001$ \\
\hline Stress & $13(72.2)$ & $23(85.2)$ & $<0.448$ \\
\hline Migraine & $0(0)$ & $2(7.4)$ & $<0.001$ \\
\hline Diabetes mellitus & $0(0)$ & $1(3.7)$ & $<0.001$ \\
\hline Unknown & $0(0)$ & $1(3.7)$ & $<0.001$ \\
\hline Current treatment & & & 0.79 \\
\hline None & $1(5.6)$ & $2(7.4)$ & 1.00 \\
\hline Amitriptyline & $8(44.4)$ & $13(48.1)$ & 1.00 \\
\hline Doxepin & $3(16.7)$ & $2(7.4)$ & 0.36 \\
\hline Multiple & $6(33.3)$ & $7(25.9)$ & 0.74 \\
\hline Nortriptyline & $0(0)$ & $1(3.7)$ & 1.00 \\
\hline Dicyclomine & $0(0)$ & $1(3.7)$ & 1.00 \\
\hline Unknown & $0(0)$ & $1(3.7)$ & 1.00 \\
\hline Currently on treatment* & $17(94.4)$ & $22(81.5)$ & 0.37 \\
\hline Improvement in symptoms on treatment & $18(100)$ & $27(100)$ & 1.00 \\
\hline Mean improvement in pain scale (\%) & 70 & 80 & 0.8 \\
\hline Decreased hospitalizations & $17(94.4)$ & $27(100)$ & 0.40 \\
\hline Symptoms manageable & $17(94.4)$ & $27(100)$ & 0.40 \\
\hline \multicolumn{4}{|l|}{ Last hospitalization (y) } \\
\hline$<1$ & $7(38.9)$ & $11(40.7)$ & 1.00 \\
\hline $1-3$ & $10(55.5)$ & $15(55.5)$ & 1.00 \\
\hline $4-6$ & $1(5.6)$ & $1(3.7)$ & 1.00 \\
\hline Currently on narcotics & $4(22.3)$ & $1(3.7)$ & 0.14 \\
\hline Stress reduced & $14(77.8)$ & $23(85.2)$ & 0.69 \\
\hline On counseling & $6(33.3)$ & $9(33.3)$ & 1.00 \\
\hline Returned to social activities & $13(72.2)$ & $24(88.9)$ & 0.24 \\
\hline Happier than before & $16(88.9)$ & $27(100)$ & 0.16 \\
\hline
\end{tabular}

*All 18 patients $(100 \%)$ in the CHS group either stopped or decreased the marijuana intake.

CHS, cannabinoid hyperemesis syndrome; CVS, cyclic vomiting syndrome. 
University Health Science Center in El Paso. Among the patients with CHS, 55\% were Hispanic, with an average age of 35 years (IQR 26-43). Prior to CHS diagnosis, 39\% (7/18) of patients had symptoms between 4 and 10 years, and $11 \%$ of patients $(2 / 18)$ had symptoms for more than 10 years. The follow-up time was 4.2 years $(\mathrm{SD} \pm 3.03)$. When patients with $\mathrm{CHS}$ were compared with the patients with classic 'CVS', there was no significant difference in the baseline demographics and disease characteristics apart from the chronic daily use of marijuana.

In the CHS group, about two-thirds reported having coexisting 'stress' when compared with $85 \%$ in the CVS group. The most common long-term preventive medication used in both groups was amitriptyline $(44.4 \%$ vs $48.1 \%$, $\mathrm{p}=1.00$ ). All the patients in both groups reported improvement in pain, with a $70 \%$ improvement in the CHS group and an $80 \%$ improvement in the CVS group $(p=0.86)$. In patients with CHS, $61 \%$ did not have any hospitalizations within the past year. Most patients in both groups reported reduction of stress $(77.8 \%$ vs $85.2 \%, \mathrm{p}=0.69)$, ability to participate in social activities $(72.2 \%$ vs $88.9 \%, p=0.24)$, and improvement in their mood $(88.9 \%$ vs $100 \%, p=0.16)$. All respondents who previously indicated they were employed prior to diagnosis were able to return to work. These data reaffirm that both these entities are responsive to appropriate treatment, and CHS is essentially reversible and 'curable' over time when marijuana is minimized or stopped.

\section{PATHOPHYSIOLOGY}

The endocannabinoid system (EBS) consists of the ligands (anandamide and 2-arachidonoyl glycerol), their biosynthesis and degradation enzymes, and their receptors cannabinoid-1 (CB1) and cannabinoid-2. The EBS is present on the vagus nerve, brainstem, and the enteric nervous system (figure 2). There is a crosstalk between the enteric nervous system and the vagus nerve, which transmits sensory signals to the brain. The sensation of nausea is through the stimulation of area postrema in the brainstem or chemoreceptor trigger zone by the vagus nerve or the chemical stimuli in the blood, which in turn stimulates the vomiting center. In addition, the stimulatory effects of cannabinoids on the pituitary-adrenal axis are centrally mediated through corticotropin-releasing hormone, along with inputs from stress-responsive limbic nuclei. ${ }^{30}$

However, for CHS, other considerations are also involved. The antiemetic effects of ligands like tetrahydrocannabinol (THC) happen by stimulation of the cannabinoid receptors in both the central nervous system (CNS) and GI system. For 'classic' CVS, the underlying concept is a dysregulation of central neural pathways and neuroendocrine mediators involved in the brain-gut pathways. The contributing factors to the pathophysiology of CHS are still not well defined, but the cumulative dose of marijuana, genetic factors, underlying psychological 'stress' including a background of post-traumatic stress disorder or a history of physical and/or sexual abuse are all considered possible 'triggers' for activating a cascade of negative feedback on the normal antiemetic property of THC. THC is also known to delay gastric emptying, which could confuse the interpretation of a scintigraphic gastric emptying study

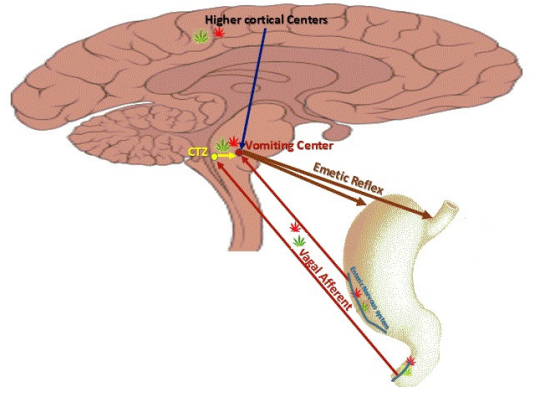

Figure 2 The endocannabinoid network, central nervous system, and enteric nervous system pathways in nausea and vomiting. Cannabinoid receptor 1 (green leaf) and receptor 2 (red leaf) are present in the enteric nervous system as well as the enteric mucosa. These receptors are also present in the central nervous system (CNS), including the brainstem, which is the main center for controlling nausea and vomiting. The brainstem also receives signals from upper CNS centers which are involved in the processing of nausea and vomiting and are affected by endocannabinoid signaling. Activation of the cannabinoid-1 (CB1) and cannabinoid-2 (CB2) receptors alleviates nausea and vomiting through central and peripheral mechanisms. In cannabinoid hyperemesis syndrome (CHS), mechanisms related to dysregulation of central neural pathways and neuroendocrine mediators involved in the afferent and efferent brain-gut pathways result in the induction of periodic nausea and vomiting attacks. CTZ, chemoreceptor trigger zone in area postrema.

if the patient smoked before the study, generally unknown to the physicians. ${ }^{31} 32$ THC is highly lipophilic and can accumulate to high concentrations in fat cells of the brain, with a long half life. It has been postulated that cannabinoids normally exert their antiemetic properties via central cannabinoid receptors in the area postrema and dorsal vagal complex and exert emetic properties via peripheral enteric receptors. ${ }^{31}$ One could speculate that the predominant effect could also be related to the dose of cannabinoids, with lower doses having antiemetic effects and higher doses causing emesis.

The other hypotheses in CHS are (A) downregulation of the cannabinoid receptors in the brain due to chronic cannabis use, (B) degradation of the cannabis ingredients into emetic metabolites, and $(\mathrm{C})$ contamination with other toxins which could exert emetogenic properties. ${ }^{73-35}$

\section{MANAGEMENT OF CHS Abortive therapy}

When patients with CHS go to ED, they undergo extensive blood work and imaging evaluations. The complications from CHS include acute renal failure, hypokalemia, hypophosphatemia, esophageal injury, including Mallory-Weiss tear, and pneumomediastinum. ${ }^{36}{ }^{37}$ Intravenous hydration and electrolyte corrections are the initial goals. Parenteral narcotic administration to treat abdominal pain is not recommended since narcotics can worsen hyperemesis and promote addictive behavior. Repeated abdominal imaging studies, as well as extensive laboratory studies, are most often unremarkable. 


\section{Conventional antiemetics}

Standard antiemetics, such as ondansetron and promethazine, are most commonly used in acute care settings. ${ }^{8} \mathrm{~A}$ systematic review by Richards et al concluded that conventional antiemetics alone are frequently ineffective, while intravenous benzodiazepines have better efficacy. ${ }^{38}$

\section{Benzodiazepines}

Benzodiazepines such as lorazepam have been successfully used in the acute management of CHS. ${ }^{34}{ }^{38-40}$ In the ED, intravenous lorazepam $(1-2 \mathrm{mg})$ is given every $4-6$ hours as needed. At discharge, lorazepam is typically prescribed as oral tablets in the dose of $0.5-1 \mathrm{mg}$ every 6-8 hours. Benzodiazepines are gamma-aminobutyric acid (GABA) agonists with antiemetic effects through the inhibition of medullary and vestibular nuclei. ${ }^{41}$ The benzodiazepines also have anxiolytic and sedative properties, which are helpful in the setting of the abnormal sympathetic nervous system response to stress-the sedation results in no vomiting and loss or no awareness of ongoing pain. In the pediatric literature, there are recommendations to essentially 'comatose' patients in the intensive care unit setting. GABA exerts its effect in the CNS and GI tract and affects the motility, mucosal hemostasis, and release of chemical substances such as histamine, prostaglandin, acetylcholine, and serotonin. ${ }^{74}$ Cannabinoids acting via the cannabinoid receptor inhibit the GABA-mediated neurotransmission, which decreases the negative inhibition on the dopaminergic neurons and enhances the dopamine release in both the striatum and mesolimbic systems and decreases extracellular glutamate. ${ }^{4-45}$ These result in symptoms of anxiety, tremors, and paranoia in some cannabis users. In addition, abrupt cannabis cessation can cause catatonia from GABA and dopamine D2 receptor hypoactivity, and glutamate $\mathrm{N}$-methyl-D-aspartate receptor hyperactivity, which can be treated with benzodiazepines. ${ }^{46} 47$ The adverse effects of benzodiazepines include oversedation, hypoventilation, dizziness, confusion, and incoordination.

\section{Haloperidol}

Haloperidol is frequently used as an off-label antiemetic. ${ }^{48}$ Haloperidol is commonly used to treat the agitated patient, and it is an effective sedative at the dose of $2-10 \mathrm{mg}$ intravenously as needed up to $30 \mathrm{mg} / \mathrm{d}$. ${ }^{49}$ Its mechanism of action is by $\mathrm{D} 2$ receptors antagonism in the mesolimbic and mesocortical pathways. Due to these sedative and antiemetic properties, haloperidol has been used to treat hyperemesis in patients with CHS, usually at the dose of $0.5-2 \mathrm{mg}$ intravenously every 6 hours as needed. ${ }^{50-52}$ In addition, the interactions between dopamine and CB1 signaling mechanisms may play a role in the efficacy of haloperidol in CHS. ${ }^{53} 54$ There are anecdotal data supporting the successful role of haloperidol (5 mg daily oral) in the management of CHS, even in outpatient settings. ${ }^{50}$ Some of the most important adverse reactions with haloperidol include extrapyramidal reactions, parkinsonism, dystonia, and QTc prolongation. ${ }^{55}$ Intravenous haloperidol is associated with dose-dependent QT prolongation at doses $>2 \mathrm{mg} .{ }^{56}$ Furthermore, it has been reported that long QT syndrome occurs in 513 per 100,000 cases of teenage cannabis users. ${ }^{48}$
Capsaicin

Capsaicin is found in chili pepper, and it binds to transient receptor potential vanilloid-1 (TRPV1) receptors. TRPV1 receptors are found throughout in GI tract and medullary vomiting center, often in proximity to CB1 receptors, which suggests a functional interaction. ${ }^{57}$ TRPV1 receptors are involved in the transmission and modulation of pain. Capsaicin is applied as a topical cream on the abdomen that produces a sensation of heat on contact with the skin and thus counteracts the abdominal pain. ${ }^{58}$ Recently, the Food and Drug Administration (FDA) approved an 8\% capsaicin patch for the treatment of diabetic peripheral neuropathic pain in the foot. ${ }^{59}$ This may be potentially applicable to treat abdominal pain in CVS or CHS. Side effects are skin irritation and blistering at the site of application.

\section{Other agents}

Although other agents will be reviewed, once the hyperemesis phase starts, the efficacy of these antiemetics is limited. The over-riding recommendation is to concurrently induce sedation and/or sleep through the approaches already addressed. Medications such as aprepitant, olanzapine, and triptans are considered as potential future therapeutic targets for treating CVS or CHS. Aprepitant is a neurokinin-1 receptor antagonist that has been recommended in moderate-severe CVS as an alternate prophylactic medication. ${ }^{60}$ So far, there has been 1 open-label trial of aprepitant used to treat CVS in children and adolescents refractory to conventional treatment. ${ }^{60}$ Olanzapine is a second-generation antipsychotic with an off-label use for chemotherapy-induced nausea or vomiting. ${ }^{61}$ Its efficacy is mediated through combined antagonism of dopamine and serotonin type 2 receptors. So far, there are some case series that have reported its benefit in treating CHS. ${ }^{38}$ Sumatriptan is an antimigraine medication with serotonin agonistic action that has been used as an abortive therapy in migraine-related CVS. ${ }^{62}$ So far, there are no published reports of its use in CHS.

\section{Prophylactic approach}

The long-term management in CHS is a 'prophylactic' concept, focused on reducing and preventing future hyperemesis episodes. $^{11}$

\section{Treatment of CUD}

It is of paramount importance that the patient stops using cannabis to treat CHS. The involvement of the patient's family can provide additional history, therapeutic support, assist in monitoring the patient's progress and adherence to treatment. The recommended first-line strategy is psychosocial interventions such as cognitive-behavioral therapy (CBT) or motivational enhancement therapy. ${ }^{63}$ The goal is to enhance motivation to stop cannabis use, improve social skills, improve interpersonal functioning, manage painful feelings, and education about the consequences of cannabis use. If the patient does not have access to these structured psychotherapy interventions, they can be referred to addiction counseling and mutual-help groups such as Marijuana Anonymous. ${ }^{64}$ For patients who failed psychosocial interventions, a trial of adjunctive gabapentin can be used in adults and $\mathrm{N}$-acetylcysteine in adolescents. ${ }^{656} \mathrm{An}$ 
important issue to consider is withdrawal symptoms after the patient stops using cannabis, especially in heavy users. ${ }^{67}$ These might be the reasons for the patient's resistance to stopping or result in recidivism. The withdrawal symptoms can be severe enough to interfere with daily life, including loss of appetite, insomnia, anxiety, depression, and physical tension. ${ }^{67}$ The use of tricyclic antidepressant (TCA) regimen is effective in reducing and stopping THC.

\section{TCAs for initiating and sustaining THC withdrawal}

Most of the data on the effectiveness of TCAs are based on the research conducted by our group with amitriptyline as the pharmacoprophylactic agent of choice in the longterm management of patients with 'classic' CVS. ${ }^{1138}$ Other TCAs such as nortriptyline and doxepin can be used as second-line and third-line agents, respectively, due to side effects or intolerance to amitriptyline, specifically excessive tiredness, intermittent palpitations and nightmares. ${ }^{27}$ TCA decreases cholinergic neurotransmission and modulating alpha-2-adrenoreceptors, thereby reducing the sympathetic nervous system and brain-gut autonomic dysfunction. ${ }^{13} 6869$ Amitriptyline is initially started at a very low dose of 10 $\mathrm{mg}$ at night, and the dose is incrementally titrated up by $10 \mathrm{mg}$ doses every 1-2 weeks to titrate to the desired therapeutic effect. ${ }^{27}$ The rationale behind this slow uptitration of the amitriptyline dose allows adaption by the body so as to minimize the anticholinergic effects such as dry mouth, somnolence, constipation, postural hypotension, palpitations, chronic fatigue, blurred vision, nightmares and mild hallucinations. ${ }^{27}$ The goal is to achieve the prevention of vomiting cycles at the lowest possible dose. Typically, the patients achieve symptom control at a dose ranging from 50 to $200 \mathrm{mg} / \mathrm{d}^{27}$ Amitriptyline needs to be used with care in patients with cardiac arrhythmias, recent myocardial infarction, mania, and severe liver disease. ${ }^{70}$ With our dosing recommendations for amitriptyline in CHS, specifically incremental and slow increases in dose, we have not observed clinically significant arrhythmias. Amitriptyline is listed as a category $\mathrm{C}$ drug in pregnancy by the FDA and, therefore, is not recommended during pregnancy.

The patients should be simultaneously counseled to taper the cannabis use with a goal to achieve abstinence from cannabis within 3-6 months. Unwillingness to taper and stop marijuana can sabotage the amitriptyline therapy. Once the patient is in remission with no attacks of CHS for a period of 6-12 months on amitriptyline therapy, the dose can be tapered by $10 \mathrm{mg} / \mathrm{mo}$ decrements, and in approximately 1 year, amitriptyline can be stopped entirely. Nortriptyline and doxepin are reported to have less adverse events, but still with good therapeutic benefits. ${ }^{27}$

\section{Adjunctive measures}

\section{Management of mood disorders}

Background anxiety and depression are commonly associated with patients with $\mathrm{CHS}^{71}$ The stereotypic but unpredictable symptoms in CHS, especially during the hyperemesis phase, can mimic panic disorder. This is supported by the fact that the patients with CHS respond well to benzodiazepines during acute attacks. Between the attacks, importance should be given to address the underlying mood disorders. The commonly used anxiety rating tool is the Hamilton Rating Scale for Anxiety, and the Zung Depression Inventory is used to assess the severity of depression. $^{72} 73$

The treatment of anxiety has been shown to reduce healthcare utilization and reduce attacks in patients with CVS. ${ }^{74}$ The psychotherapies that are most effective include CBT and interpersonal psychotherapy. ${ }^{75}$ Mind-body focused modalities such as mindfulness meditation, hypnotherapy, biofeedback, and movement-based therapies (yoga, Pilates) are helpful in building resilience to stressors. ${ }^{76}$ The classes of antidepressants used to treat mood disorders include selective serotonin reuptake inhibitors, serotonin-norepinephrine reuptake inhibitors (SNRIs), atypical antidepressants, and TCAs. Antidepressants such as duloxetine (SNRI) and mirtazapine (atypical) are more commonly used. Buspirone is effective in generalized anxiety disorder, and it may take up to 4-6weeks to achieve maximal efficacy. ${ }^{77}$ Lorazepam is typically usually used as adjunctive therapy. ${ }^{78}$ For the treatment of anxiety or depression, a combination of pharmacotherapy and psychotherapy has been found to be more effective than either of these treatments alone. ${ }^{79}$ Most of the patients with CHS attribute the vomiting cycles to stress and anxiety. Hence, it is of paramount importance to address the stress and anxiety component while reducing the THC use.

\section{Nutrition during acute episodes}

In hospitalized patients with CHS during the hyperemesis phase, they are kept in the nothing by mouth status until their symptoms improve. During recovery, they are started with clear liquids and then slowly advanced back to the regular diet. If they are managed at home, then they are encouraged to drink plenty of liquids that contain glucose and electrolytes, such as broths or oral rehydration solutions, between the attacks of vomiting to keep them hydrated. Overall, patients with CHS do not lose weight because of the cyclical nature of the entity, which means that there are many asymptomatic weeks where oral intake makes up for the days of vomiting attacks.

\section{Other aspects of management}

Non-response to the standard therapies can occur in approximately $15 \%$ of the patients. ${ }^{12}$ The main risk factors for nonresponse to amitriptyline are psychiatric disorder, chronic narcotic, and ongoing surreptitious marijuana use. These issues may require comanagement with a psychologist or psychiatrist and focus on more aggressive treatment of depression.

\section{LONG-TERM OUTCOME}

We have observed 2 treatment patterns during long-term follow-up. One group of patients requires a further slow increase in their maintenance dose to achieve stability over time since they have developed dose tolerance resulting in 'breakthrough' vomiting cycles. Once stability is achieved with patients on TCA therapy and their symptoms are controlled with no ED visits for at least 1 year, then we have been able to successfully taper to a lower dose or even stop amitriptyline usually over a period of 1 year. An extra motivation for female patients to taper off amitriptyline is for planning a pregnancy. Our extensive experience indicates more than $40 \%$ of the patients can actually stop all treatments over time. ${ }^{29}$

\section{FUTURE TREATMENT OPTIONS}

Synthetic delta-9-tetrahydrocannabinol agents such as Marinol (dronabinol) are used in the 'detox' program, and they have 
a more controlled antiemetic effect than smoking cannabis. Psychotherapies and meditation, as well as incorporating the new treatment concept of virtual reality, may be of benefit in CHS. $^{80}$

\section{MANAGEMENT PEARLS FOR LONG-TERM SUCCESS}

The crux of long-term management depends on physician commitment, availability, and coordinating organized follow-up visits. A strong working relationship, trust, and rapport between the patient and the physician are of utmost importance. ${ }^{81}$ These are 'old school' principles of medical practice that are crucial in determining successful outcomes in these patients. Studies show that when patients trust their physicians, they will be more likely to disclose all of their health-related behaviors, including stigmatizing or shameful behaviors, and are more likely to follow their physician's recommendations. ${ }^{82}$ In addition, the patient will accept the diagnosis of CHS when no other physician has proposed this and, in turn, will not continue 'searching' for the 'right' diagnosis and incur unnecessary medical expenses and inappropriate diagnoses and treatments.

\section{CONCLUSIONS}

The 2 entities of 'classic' CVS and CHS are comparable in their clinical presentation and response to pharmacologic therapies and outcomes. As the use of illicit and medical cannabis increases, we can expect the prevalence of CHS to rise as well as increased healthcare utilization. It has been more than 15 years since CHS was first reported, but it still remains an unfamiliar and under-reported clinical entity among physicians worldwide. The contribution of cannabis has to be elicited in a thorough history to establish a crucial piece of diagnostic evidence. In the future, there will be a greater understanding of the EBS, thus leading to better strategies and therapies for CHS. In the meantime, education and awareness are the keys to impacting this entity, and physicians in the ED should be the focus of this approach.

Contributors MG: conceptualization, drafting and critical revision of the manuscript. JS, MB: substantial revision of the manuscript. RMC: conceptualization, substantial revision of the manuscript, supervision. All authors approved the submitted version. All authors agreed both to be personally accountable for the author's own contributions and to ensure that questions related to the accuracy or integrity of any part of the work, even ones in which the author was not personally involved.

Funding The authors have not declared a specific grant for this research from any funding agency in the public, commercial or not-for-profit sectors.

Competing interests None declared.

Patient consent for publication Obtained.

Provenance and peer review Not commissioned; externally peer reviewed.

ORCID iD

Mahesh Gajendran http://orcid.org/0000-0003-0932-4848

\section{REFERENCES}

1 Ellens JH. Seeking the Sacred with Psychoactive Substances: Chemical Paths to Spirituality and to God [2 volumes]: Chemical Paths to Spirituality and to God. ABC-CLIO, 2014.

2 Zias J, Stark H, Sellgman J, et al. Early medical use of cannabis. Nature 1993;363:215

3 Musto DF. The marihuana Tax act of 1937. Arch Gen Psychiatry 1972:26:101-8.

4 Drossman DA, Hasler WL. Rome IV-Functional Gi disorders: disorders of gutbrain interaction. Gastroenterology 2016;150:1257-61.
5 Stanghellini V, Chan FKL, Hasler WL, et al. Gastroduodenal disorders. Gastroenterology 2016;150:1380-92.

6 Allen JH, de Moore GM, Heddle R, et al. Cannabinoid hyperemesis: cyclical hyperemesis in association with chronic cannabis abuse. Gut 2004;53:1566-70

7 Bashashati M, McCallum RW. Neurochemical mechanisms and pharmacologic strategies in managing nausea and vomiting related to cyclic vomiting syndrome and other gastrointestinal disorders. Eur J Pharmacol 2014;722:79-94.

8 Richards JR. Cannabinoid hyperemesis syndrome: pathophysiology and treatment in the emergency department. J Emerg Med 2018;54:354-63.

9 Darmani NA. Cannabinoid-Induced hyperemesis: a conundrum — from clinical recognition to basic science mechanisms. Pharmaceuticals 2010:3:2163-77.

10 A. Galli J, Andari Sawaya R, K. Friedenberg F. Cannabinoid hyperemesis syndrome. CDAR 2011;4:241-9.

11 McCallum RW, Cooper CJ. Cyclic vomiting syndrome: diagnostic criteria and insights into long term treatment outcomes. Practical Gastroenterology, 2015.

12 Namin F, Patel J, Lin Z, et al. Clinical, psychiatric and manometric profile of cyclic vomiting syndrome in adults and response to tricyclic therapy. Neurogastroenterol Motil 2007;19:196-202.

13 Prakash C, Clouse RE. Cyclic vomiting syndrome in adults: clinical features and response to tricyclic antidepressants. Am J Gastroenterol 1999:94:2855-60.

14 Hejazi RA, Lavenbarg TH, Foran P, et al. Who are the nonresponders to standard treatment with tricyclic antidepressant agents for cyclic vomiting syndrome in adults? Aliment Pharmacol Ther 2010;31:295-301.

15 Simonetto DA, Oxentenko AS, Herman ML, et al. Cannabinoid hyperemesis: a case series of 98 patients. Mayo Clin Proc 2012;87:114-9.

16 Hejazi RA, Lavenbarg TH, McCallum RW. Spectrum of gastric emptying patterns in adult patients with cyclic vomiting syndrome. Neurogastroenterol Motil 2010;22:e1338:1298-338.

17 Goyal H, Singla U, Gupta U, et al. Role of cannabis in digestive disorders. Eur J Gastroenterol Hepatol 2017;29:135-43.

18 Sperber AD, Bangdiwala SI, Drossman DA, et al. Worldwide prevalence and burden of functional gastrointestinal disorders, results of Rome Foundation global study. Gastroenterology 2020. doi:10.1053/j.gastro.2020.04.014. [Epub ahead of print: 12 Apr 2020].

19 Aziz I, Palsson OS, Whitehead WE, et al. Epidemiology, clinical characteristics, and associations for Rome IV functional nausea and vomiting disorders in adults. Clin Gastroenterol Hepatol 2019;17:878-86.

20 Compton WM, Saha TD, Conway KP, et al. The role of cannabis use within a dimensional approach to cannabis use disorders. Drug Alcohol Depend 2009;100:221-7.

21 Perisetti A, Rimu AH, Khan SA, et al. Role of cannabis in inflammatory bowel diseases. Ann Gastroenterol 2020;33:134-44.

22 Al-Shammari M, Herrera K, Liu X, et al. Effects of the 2009 Medical Cannabinoid Legalization Policy on Hospital Use for Cannabinoid Dependency and Persistent Vomiting. Clin Gastroenterol Hepatol 2017; 15:1876-81.

23 Annual prevalence of the use of drugs by region and globally. Available: https://dataunodc.un.org/drugs/prevalence_regional

24 Azofeifa A, Mattson ME, Schauer G, et al. National estimates of marijuana use and related indicators - National survey on drug use and health, United States, 2002-2014. MMWR Surveill Summ 2016;65:1-28.

25 Madireddy S, Patel RS, Ravat V, et al. Burden of comorbidities in hospitalizations for cannabis Use-associated intractable vomiting during Postlegalization period. Cureus 2019;11:e5502.

26 Monte AA, Shelton SK, Mills E, et al. Acute illness associated with cannabis use, by route of exposure: an observational study. Ann Intern Med 2019;170:531-7.

27 Hejazi RA, Reddymasu SC, Namin F, et al. Efficacy of tricyclic antidepressant therapy in adults with cyclic vomiting syndrome: a two-year follow-up study. J Clin Gastroenterol 2010;44:18-21.

28 Sorensen CJ, DeSanto K, Borgelt L, et al. Cannabinoid hyperemesis syndrome: diagnosis, pathophysiology, and Treatment-a systematic review. J Med Toxicol 2017;13:71-87.

29 Sifuentes JD, McCallum RW. Mo1525 long term follow up of cyclic vomiting syndrome: evidence for symptom control and improved quality of life. Gastroenterology 2020;158:S-881-881.

30 Martín-Calderón JL, Muñoz RM, Villanúa MA, et al. Characterization of the acute endocrine actions of (-)-11-hydroxy-delta8-tetrahydrocannabinoldimethylheptyl (HU-210), a potent synthetic cannabinoid in rats. Eur J Pharmacol 1998:344:77-86.

31 Massa F, Storr M, Lutz B. The endocannabinoid system in the physiology and pathophysiology of the gastrointestinal tract. J Mol Med 2005;83:944-54. 
32 Duncan M, Davison JS, Sharkey KA. Review article: endocannabinoids and their receptors in the enteric nervous system. Aliment Pharmacol Ther 2005:22:667-83.

33 Pattathan MB, Hejazi RA, McCallum RW. Association of marijuana use and cyclic vomiting syndrome. Pharmaceuticals 2012;5:719-26.

34 Choung RS, Locke GR, Lee RM, et al. Cyclic vomiting syndrome and functional vomiting in adults: association with cannabinoid use in males. Neurogastroenterol Motil 2012;24:20-1.

35 Sharkey KA, Darmani NA, Parker LA. Regulation of nausea and vomiting by cannabinoids and the endocannabinoid system. Eur J Pharmacol 2014;722:134-46.

36 Habboushe J, Sedor J. Cannabinoid hyperemesis acute renal failure: a common sequela of cannabinoid hyperemesis syndrome. Am J Emerg Med 2014;32:690. e1-690.e2.

37 Cadman PE. Hypophosphatemia in users of cannabis. Am J Kidney Dis 2017:69:152-5.

38 Richards JR, Gordon BK, Danielson AR, et al. Pharmacologic treatment of cannabinoid hyperemesis syndrome: a systematic review. Pharmacotherapy 2017;37:725-34

39 Nicolson SE, Denysenko L, Mulcare JL, et al. Cannabinoid hyperemesis syndrome: a case series and review of previous reports. Psychosomatics 2012;53:212-9.

40 Contreras Narváez C, Mola Gilbert M, Batlle de Santiago E, et al. Cannabinoid hyperemesis syndrome. A report of six new cases and a summary of previous reports. Adicciones 2016;28:90-8.

41 Singh P, Kuo B. Central aspects of nausea and vomiting in Gi disorders. Curr Treat Options Gastroenterol 2016;14:444-51.

42 Maldonado R, Berrendero F, Ozaita A, et al. Neurochemical basis of cannabis addiction. Neuroscience 2011;181:1-17.

43 Hoffman AF, Lupica CR. Mechanisms of cannabinoid inhibition of synaptic transmission in the hippocampus. J Neurosci 2000;20:2470-9

44 Deshpande LS, Blair RE, DeLorenzo RJ. Prolonged cannabinoid exposure alters $G A B A(A)$ receptor mediated synaptic function in cultured hippocampal neurons. Exp Neurol 2011:229:264-73.

45 McCallum RW, Bashahati M. Cannabis in gastrointestinal disorders. Pract Gastroenterol 2014:38:36-46.

46 Caudron M, Rolland B, Deheul S, et al. Catatonia and cannabis withdrawal: a case report. Subst Abus 2016:37:188-9.

47 Sienaert P, Dhossche DM, Vancampfort D, et al. A clinical review of the treatment of catatonia. Front Psychiatry 2014;5:181.

48 Ramphul K, Joynauth J. Cardiac arrhythmias among teenagers using cannabis in the United States. Am J Cardiol 2019:124:1966.

49 Powney MJ, Adams CE, Jones H. Haloperidol for psychosis-induced aggression or agitation (rapid tranquillisation). Cochrane Database Syst Rev 2012;11:CD009377

50 Witsil JC, Mycyk MB, Haloperidol MMB. Haloperidol, a novel treatment for cannabinoid hyperemesis syndrome. Am J Ther 2017;24:e64-7.

51 Jones JL, Abernathy KE. Successful treatment of suspected cannabinoid hyperemesis syndrome using haloperidol in the outpatient setting. Case Rep Psychiatry 2016:2016:1-3.

52 Hickey JL, Witsil JC, Mycyk MB. Haloperidol for treatment of cannabinoid hyperemesis syndrome. Am J Emerg Med 2013;31:1003.e5-1003.e6.

53 Schulze DR, Carroll FI, McMahon LR. Interactions between dopamine transporter and cannabinoid receptor ligands in rhesus monkeys. Psychopharmacology 2012;222:425-38.

54 Desai RI, Thakur GA, Vemuri VK, et al. Analysis of tolerance and behavioral/ physical dependence during chronic CB1 agonist treatment: effects of CB1 agonists, antagonists, and noncannabinoid drugs. J Pharmacol Exp Ther 2013:344:319-28

55 Stroup TS, Gray N. Management of common adverse effects of antipsychotic medications. World Psychiatry 2018;17:341-56.

56 Ozeki Y, Fujii K, Kurimoto N, et al. Qtc prolongation and antipsychotic medications in a sample of 1017 patients with schizophrenia. Prog Neuropsychopharmacol Biol Psychiatry 2010;34:401-5.

57 Yang F, Zheng J. Understand spiciness: mechanism of TRPV1 channel activation by capsaicin. Protein Cell 2017;8:169-77.
58 Dezieck L, Hafez Z, Conicella A, et al. Resolution of cannabis hyperemesis syndrome with topical capsaicin in the emergency department: a case series. Clin Toxicol 2017:55:908-13.

59 U.S. Food and Drug Administration Drug Approval Package for capsaicin 8\% patch. Available: https://www.accessdata.fda.gov/drugsatfda_docs/nda/2009/ 022395_qutenza_toc.cfm [Accessed 8 Feb 2020].

60 Cristofori F, Thapar N, Saliakellis E, et al. Efficacy of the neurokinin-1 receptor antagonist aprepitant in children with cyclical vomiting syndrome. Aliment Pharmacol Ther 2014:40:309-17.

61 Hashimoto H, Abe M, Tokuyama O, et al. Olanzapine $5 \mathrm{Mg}$ plus standard antiemetic therapy for the prevention of chemotherapy-induced nausea and vomiting (J-FORCE): a multicentre, randomised, double-blind, placebocontrolled, phase 3 trial. Lancet Oncol 2020;21:242-9.

62 Kovacic K, Sood M, Venkatesan T. Cyclic vomiting syndrome in children and adults: what is new in 2018? Curr Gastroenterol Rep 2018;20:46.

63 Gates PJ, Sabioni P, Copeland J, et al. Psychosocial interventions for cannabis use disorder. Cochrane Database Syst Rev 2016:CD005336.

64 Stephens RS, Roffman RA, Simpson EE. Treating adult marijuana dependence: test of the relapse prevention model. J Consult Clin Psychol 1994;62:92-9.

65 Mason BJ, Crean R, Goodell V, et al. A proof-of-concept randomized controlled study of gabapentin: effects on cannabis use, withdrawal and executive unction deficits in cannabis-dependent adults. Neuropsychopharmacology 2012:37:1689-98

66 Gray KM, Sonne SC, McClure EA, et al. A randomized placebo-controlled trial of $\mathrm{N}$-acetylcysteine for cannabis use disorder in adults. Drug Alcohol Depend 2017:177:249-57.

67 Budney AJ, Novy PL, Hughes JR. Marijuana withdrawal among adults seeking treatment for marijuana dependence. Addiction 1999:94:1311-22.

68 Lee LYW, Abbott L, Mahlangu B, et al. The management of cyclic vomiting syndrome: a systematic review. Eur J Gastroenterol Hepatol 2012;24:1001-6.

69 Prakash C, Staiano A, Rothbaum RJ, et al. Similarities in cyclic vomiting syndrome across age groups. Am J Gastroenterol 2001;96:684-8.

70 Marshall JB, Forker AD. Cardiovascular effects of tricyclic antidepressant drugs: therapeutic usage, overdose, and management of complications. Am Heart J 1982;103:401-14

71 Roca-Pallín JM, López-Pelayo H, Sugranyes G, et al. Cannabinoid hyperemesis syndrome. CNS Neurosci Ther 2013;19:994-5.

72 Moses S. Hamilton anxiety scale. Family Practice Notebook, 2001.

73 Beck JS, Beck AT. Cognitive therapy: basics and beyond. Guilford press New York, 1995

74 Bhandari S, Venkatesan T. Clinical characteristics, comorbidities and hospital outcomes in hospitalizations with cyclic vomiting syndrome: a nationwide analysis. Dig Dis Sci 2017;62:2035-44.

75 Parikh SV, Segal ZV, Grigoriadis S, et al. Canadian network for mood and anxiety treatments (CANMAT) clinical guidelines for the management of major depressive disorder in adults. II. psychotherapy alone or in combination with antidepressant medication. J Affect Disord 2009;117 Suppl 1:S15-25.

76 Slutsker B, Konichezky A, Gothelf D. Breaking the cycle: cognitive behavioral therapy and biofeedback training in a case of cyclic vomiting syndrome. Psychol Health Med 2010;15:625-31.

77 Gammans RE, Mayol RF, LaBudde JA. Metabolism and disposition of buspirone. Am J Med 1986:80:41-51.

78 Davidson JR. Pharmacotherapy of generalized anxiety disorder. J Clin Psychiatry 2001;62:46-50.

79 Cuijpers P, van Straten A, Warmerdam L, et al. Psychotherapy versus the combination of psychotherapy and pharmacotherapy in the treatment of depression: a meta-analysis. Depress Anxiety 2009;26:279-88.

80 Birckhead B, Khalil C, Liu X, et al. Recommendations for methodology of virtua reality clinical trials in health care by an international Working group: iterative study. JMIR Ment Health 2019;6:e11973.

81 Fuertes JN, Mislowack A, Bennett J, et al. The physician-patient working alliance. Patient Educ Couns 2007:66:29-36.

82 Anderson LA, Dedrick RF. Development of the trust in physician scale: a measure to assess interpersonal trust in patient-physician relationships. Psychol Rep 1990;67:1091-100 